\title{
DESIGN E ENSINO: análise das imagens do caderno cultura e trabalho da educação de jovens e adultos
}

\author{
Mariano Lopes de Andrade Neto \\ PPG Design - FAAC - UNESP \\ mlaneto@gmail.com \\ Carolina Vaitiekunas Pizarro \\ PPG Design - FAAC - UNESP \\ caroldipp@gmail.com \\ Paula da Cruz Landim \\ PPG Design - FAAC - UNESP \\ paula@ faac.unesp.br \\ Cassia Leticia Carrara Domiciano \\ PPG Design - FAAC - UNESP \\ cassiacarrara@gmail.com
}

Resumo: A presença de imagens no cotidiano do Homem remonta aos primeiros registros de comunicação com as pinturas rupestres e com o passar do tempo para além dessa finalidade o emprego de imagens tornouse um instrumento de representação, divulgação e instrução. Seja na complementação de textos verbais ou mesmo no formato de um texto visual em si, para que se possa extrair o máximo de possibilidades de leitura de uma imagem torna-se essencial o seu adequado planejamento. Tal postura deve ser adotada quaisquer que sejam os objetivos finais de seu uso, especialmente se a formulação da mesma tiver como foco o ensino e aprendizagem. Dentro da área de ensino a modalidade Educação de Jovens e Adultos merece atenção, dado o número reduzido de materiais didáticos planejados para atender esse público. A partir do contato com os materiais didáticos oficiais produzidos pelo Governo Federal e voltados à EJA, o presente artigo tem como objetivo analisar sob a perspectiva do design, a seleção de imagens empregadas no projeto gráfico desse material tomando como objeto de análise um dos treze cadernos editados e distribuídos para uso em sala de aula pelos alunos. A pesquisa configura um estudo de caso de abordagem qualitativa e a análise das imagens foi realizada com base em quatro etapas do método de Barros (2009) considerando os níveis de expressão propostos por Dondis (2007) como base para avaliação da relação entre informações verbais e não verbais presentes no conteúdo pesquisado, avaliando por fim a integração do 
conteúdo verbal e visual no mesmo. Pretende-se que os resultados da pesquisa promovam a ampliação das discussões acerca de projetos gráficos voltados à educação de jovens e adultos, aprimorando a elaboração de novos projetos por parte dos designers.

Palavras-chave: Design, ilustração, material didático, EJA.

\section{INTRODUÇÃO}

O uso da imagem sempre esteve presente na transmissão do conhecimento humano, desde os primeiros registros de comunicação com as pinturas rupestres. Ao longo da história essa função inicial se manteve, porém nas mais diversas abordagens. Atualmente encontram-se variados suportes e empregos da imagem como informação, seja para divulgar, representar ou instruir o público ao qual se destina.

Para atender às necessidades de informação e formação, os meios de comunicação recorrem às diferentes técnicas, estilos e representações disponíveis. Mas até que ponto essas escolhas são planejadas? De acordo com Barros e Costa (2012, p.42) diversos trabalhos têm apontado para necessidade de se atentar para as diferentes linguagens presentes em um texto, como no caso da visual. Ela, assim como a linguagem textual, demanda familiaridade e treinamento para sua interpretação consciente e crítica. Nesse sentido, o emprego da linguagem visual no ambiente de ensino e aprendizagem já é muito comum e, particularmente, constante nos livros didáticos e outros recursos pedagógicos. Entretanto, BELMIRO $(2000$, p.16) revela que:

[...] o uso das imagens nos livros didáticos sofre uma tremenda redução de suas possibilidades interpretativas, pela adaptação a uma configuração analítica que aponta para um modo de compreensão próprio de um objeto de estudo que é a linguagem verbal. A subordinação a um padrão conceitual que não lhes é próprio faz as imagens se ajustarem a uma lógica textual de produção de sentidos linear, argumentativa e unívoca.

Pesquisas recentes (AMARAL e FISCHER, 2013; ANDRADE NETO et. al., 2012; BARROS e COSTA, 2012; COUTINHO, LOPES e CADENA, 2011; MELLO, 2010; MORAES, 2010; TEIXEIRA e BRITO, 2010) confirmam essa necessidade de uma maior atenção por parte dos designers no que tange a linguagem visual nos livros didáticos, incluindo-se no contexto do projeto - e de maneira indissociável a ele - o emprego adequado de imagens na composição do conteúdo. Ainda mais quando observado o estudo de BARROS e COSTA (2012, p.54), no qual os livros analisados pouco contribuíam para o desenvolvimento das capacidades específicas voltadas ao letramento visual dos estudantes. Os autores ainda complementam:

Acreditamos que sejam necessárias atividades que se proponham a ir além da leitura do verbal escrito, possibilitando ao aluno apropriar-se de diversificadas formas de letramentos a fim de responder às exigências contemporâneas de leitura, posicionando-se criticamente nas mais diversas situações ou contextos (BARROS e COSTA, 2012, p.54). 
No caso do ensino de adultos, as demandas de análises dos materiais didáticos diferem do ensino infantil pelo complexo cenário que envolve a Educação de Jovens e Adultos, como explicado no referencial desse artigo. A princípio entende-se a produção didática destinada a EJA como aquela destinada ou produzida visando os processos educativos de jovens ou adultos, que são analfabetos ou possuem pouca escolaridade. De acordo com Mello (2010, p.24), os balanços sobre as pesquisas dedicadas a EJA revelam um espaço reduzido dedicado à análise dos materiais didáticos, que são compreendidos como apenas um elemento do total de projetos mais amplos, não sendo objeto de uma atenção particular. O levantamento para a pesquisa do autor (op cit, p.24) ainda revelou que são escassos os estudos que abordam a questão da produção de materiais didáticos especificamente para a EJA.

A partir do contato com os materiais didáticos oficiais produzidos pelo Governo Federal e voltados à EJA, o presente artigo tem como objetivo analisar sob a perspectiva do design, a seleção de imagens para o projeto gráfico desse material. 0 objeto de análise compreendeu um dos treze cadernos editados e distribuídos para uso em sala de aula pelos alunos, o caderno Cultura e Trabalho.

O método empregado, apoiado no trabalho de Barros (2009), visa conhecer o conteúdo e reconhecer as funções das imagens presentes no caderno selecionado. Para tanto a Teoria da Sintaxe da Linguagem Visual de Dondis (2007) foi utilizada como base de análise. Com isso, espera-se a partir da perspectiva do design, reconhecer a contribuição do material analisado para a formação e a crítica da linguagem visual.

\section{REFERENCIAL TEÓRICO}

\subsection{0 uso de imagens no ensino}

$\mathrm{Na}$ atualidade é parte do cotidiano estar em contato com diversos suportes e meios de comunicação os quais se valem de imagens para a transmissão de informações, conceitos e conhecimento em diferentes níveis e em diversos campos da vivência Humana. O poder do uso de imagens consiste em seu potencial de comunicar, contribuindo dessa maneira para a compreensão do mundo particular de cada indivíduo e seu entorno.

Segundo Freire $(2008$, p.16) o ser humano percebe uma variedade de cores, formas e movimentos; seu olhar observa os detalhes, o todo, as diferenças, as semelhanças e as mudanças, atribuindo-Ihes significado individual e/ou coletivo. "O desenvolvimento dessa prática 'educa o olhar' (visão e cognição), estimulando a ver além da aparência imediata e possibilita o reconhecimento de outros sistemas de informação presentes nos fenômenos" (op cit, p.16).

De acordo com Dondis (2007, p.183) as imagens compõem o "mundo visual" e sua produção destina-se a diversos objetivos, sendo a ampliação e melhoria da comunicação o principal deles,

[...] a maior parte do material visual produzido diz respeito à necessidade de registrar, preservar, reproduzir e identificar pessoas, lugares, objetos ou classes de dados visuais. Esses materiais são de grande utilidade para demonstrar e ensinar, tanto formal quanto informalmente. (DONDIS, 2007, p.183). 
O uso de imagens pode persuadir, orientar, contar histórias, exprimir conceitos e também instruir. Em diversos casos, a imagem pode substituir um texto visando transmitir a mensagem de maneira mais direta e veloz. Em outros, a imagem pode reforçar o conteúdo de um texto, fornecendo informação extra e permitindo que o leitor reflita e construa novas interpretações.

Assim, não basta o indivíduo identificar (ou decodificar) imagens para ser considerado fluente nos letramentos visuais, é necessário que ele as compreenda de modo construtivo, sendo sua interpretação o resultado de um julgamento. Primeiramente, cabe dizer que o processo visual ostenta componentes elementares (DONDIS, 2007, p.23), ou seja, elementos específicos afora as possíveis experiências individuais trazidas no momento da leitura da imagem. Tais elementos são o início de qualquer composição visual, pois, a partir deles, é possível criar a representação de qualquer objeto. A autora defende que a familiaridade com técnicas de comunicação visual favorece a percepção do indivíduo, de modo a torná-lo mais "perspicaz para qualquer manifestação visual" (op cit, p.25), pois com elas é possível estabelecer critérios sintáticos visuais que auxiliam na "leitura visual". Nesse sentido, a linguagem visual também possui "regras" linguísticas (ou técnicas) e unidades sintáticas (ou elementos), como na verbal. Sendo possível criar, ler e compreender imagens de modo consciente. Sendo assim, entende-se que a autora baseia sua Teoria na percepção, favorecendo o fator sensorial e pressupondo uma linguagem perceptiva universal. Todavia, nas análises desta pesquisa foi considerada também a interpretação individual, a qual deriva das particularidades culturais, de tempo e de espaço do sujeito "leitor", tendo em vistas as especificidades do grupo abordado.

De acordo com Marshall e Meachem (2010, p.86) "As pessoas normalmente observam a informação visual antes do texto, portanto, usar imagens com texto pode envolver o leitor com mais eficiência, pois ele é atraído pela parte visual". A atração exercida pelo apelo visual da imagem atua em um primeiro momento prendendo a atenção do leitor e estabelecendo na sequência a comunicação pretendida por meio do conteúdo.

Também no ambiente de ensino o potencial de uso das imagens como suporte à aprendizagem se dá de maneira importante. Os materiais didáticos utilizados em sala de aula e voltados à construção de conhecimento em linhas gerais apresentam seu conteúdo agregando informações verbais dispostas no formato de textos e visuais por meio de imagens. Seu emprego no ensino enriquece o conteúdo a ser trabalhado na medida em que auxilia o docente na mediação do conhecimento a ser construído favorecendo ao mesmo tempo a aprendizagem por parte do aluno. Como revela Coutinho, Lopes e Cadena (2011, p.6) "a combinação texto/imagem/esquema proporciona maior participação do aluno na aprendizagem, por meio da análise dessa relação". Assim, as imagens empregadas em conjunto aos textos podem fornecer detalhes adicionais ao conteúdo ou mesmo informações contextualizantes, facilitando o processo de apreensão do conhecimento.

Quando empregadas de maneira adequada, as imagens produzem uma narrativa visual paralela ao texto, complementando-o, aprimorando seu alcance e aproximando-o do universo do aluno, como destacado por Cavalcante:

A imagem possibilita uma leitura pela via da interpretação e da valorização da expressão. Potencializada, a ilustração encontra-se com o texto, estabelecendo um diálogo dinâmico. A imagem pode desempenhar diversas 
funções em relação ao seu campo de ação. Ela pode ser representativa quando está ligada à realidade; pode ser descritiva; pode narrar pela caracterização de personagens e de seus tempos, fazendo em seu percurso, com que a imagem simbólica caminhe em parceria com a expressão (CAVALCANTE in FARBIARZ et al, 2008, p. 55-56)

No que tange à produção de materiais que se valem de imagens como parte integrante do conteúdo, complementando ou ampliando o potencial do texto, como é o caso dos materiais didáticos voltado ao ensino, a sinergia entre o visual e o verbal é fator determinante no sucesso do processo de comunicação pretendido quando da elaboração do material por designers, ilustradores e editores.

Tratada como ilustração, a imagem tem a importância de ajudar na visualização agradável da página. Se há textos muito longos, ela serve para quebrar o ritmo cansativo da leitura. Além disso, ela pode sugerir leituras, apoiá-las do ponto de vista do enredo, construir formas, personagens, cenários, enfim, compor, junto com o texto verbal, um horizonte de leitura.

No livro didático, apesar do apuro com que seus projetos gráficos são confeccionados recentemente, as imagens ainda não correspondem às riquezas que um emprego adequado poderia deflagrar. Ainda são tratadas como uma mera ilustração estética, ou em alguns casos podem apresentar erros conceituais ou mesmo induções a erros de interpretação. Nesse sentido, cabe ao docente o papel de mediar também o conteúdo visual assim como do conteúdo total ensinado. Importa salientar que de acordo com Pizarro (2009, p.20), é possível a partir dessa mediação pelo professor a utilização dos erros em função inversa: estimulando a reflexão a partir dos mesmos rumos à compreensão correta do conteúdo.

Assim, um estudo de caso do uso das imagens nos materiais didáticos sob a perspectiva do design, pode fornecer indicações para o estabelecimento de práticas de leitura de textos imagéticos integradas à leitura verbal, contribuindo na construção das noções de letramento dos alunos. Para análise observou-se o método utilizado por Barros (2009). Nele a análise pautou-se nas seguintes estratégias: seleção e verificação das informações verbais - para compreender a significação do texto como um todo; organização das informações da sintaxe visual - selecionando e organizando as informações relevantes à construção da significação, etapa que será orientada pela Teoria de Dondis (2007); integração das informações verbais e não verbais relacionando-as no ato de construção dos sentidos dos textos; e percepção do sentido do todo unificado composto por meio da integração dos materiais verbais e não verbais - a organização e observação das informações que permitem ao leitor construir um todo de significação (BARROS, 2009, p.166).

Portanto, um diagnóstico preliminar sobre o uso de imagens em livro didático, produzido especificamente para atender a modalidade de educação de jovens e adultos, favorece a reflexão para uma leitura crítica do material, contribuindo para um tema ainda carente de pesquisa, como pode ser observado no tópico a seguir.

\subsection{O material didático na educação de jovens e adultos}

A sigla EJA refere-se ao processo de educação de jovens e adultos, e é reconhecida pelo governo federal como uma modalidade da Educação Básica na Lei de Diretrizes e Bases da Educação Nacional - LDB 9394/96 (BRASIL, 1996). No artigo 37 da LDB consta que "A educação de jovens e adultos será destinada àqueles que não 
tiveram acesso ou continuidade de estudos no ensino fundamental e médio na idade própria"; e complementa no artigo 38, "Os sistemas de ensino manterão cursos e exames supletivos, que compreenderão a base nacional comum do currículo, habilitando ao prosseguimento de estudos em caráter regular", cabendo destacar que "§ 2 O Os conhecimentos e habilidades adquiridos pelos educandos por meios informais serão aferidos e reconhecidos mediante exames". Ou seja, os cursos oferecidos fora do sistema escolar formal também são reconhecidos, consequentemente, observa-se uma dispersão entre as iniciativas para a EJA, oferecidas pelas mais diferentes organizações (governo federal, comunidades locais, movimentos sociais ou religiosos, sindicatos, associações, organizações não governamentais, empresas educativas, fundações educacionais, além das secretarias municipais e estaduais de educação).

Assim, essa modalidade do ensino básico possui uma série de especificidades, quando comparada à educação infantil regular, quanto ao seu público heterogêneo social e culturalmente, à sua metodologia, ao currículo, e também aos recursos didáticos utilizados.

Considerando que os livros didáticos "são todas as obras cuja intenção original é explicitamente voltada para o uso pedagógico e esta intenção é manifestada pelo autor ou editor" (LIVRES, s.d. apud MELLO, 2010, p.34), no caso da sua produção, além do mercado editorial, é preciso conhecer suas relações com o poder público.

Quanto ao mercado, é fato que não há uma ampla produção de livros didáticos para EJA pelas grandes editoras, ao contrário do que acontece com os LDs do ensino infantil. $O$ aspecto econômico pode explicar essa situação, uma vez que a "EJA não forma um mercado consumidor de livros didáticos, pois seu público escolar é constituído, em sua ampla maioria, por alunos que não possuem poder aquisitivo para adquirir livros didáticos [...]" (MELLO, 2010, p.26).

Atualmente, os poucos LDs da EJA produzidos por editoras podem ser agrupados em duas categorias: os elaborados especificamente para a EJA, e os adaptados; sendo que "As obras adaptadas formam a maioria das obras destinadas a EJA e são obras propostas inicialmente a um público escolar distinto, em geral da escola regular, e que sofreram adequações editoriais para serem destinadas a EJA" (MELLO, 2010, p.240). Ou seja, grande parte desses livros sequer é originalmente planejada para a sua função.

Sobre o poder público, em 2004 a EJA passou a ser responsabilidade da recém criada Secretaria de Educação Continuada e Diversidade, a SECAD. Período em que a produção didática recebeu outra perspectiva, com a elaboração de um material didático de caráter interdisciplinar e flexível, a coleção Cadernos de EJA, lançada em 2007 (MELLO, 2010, p.90). Foi elaborada para o ensino fundamental de jovens e adultos, da alfabetização até a oitava série. "Nela os componentes e conteúdos são organizados em torno de eixos temáticos, tais como cultura, diversidade, economia [...] entre outros" (MELLO, 2010, p.91). A coleção foi disponibilizada impressa e também pela internet no 'Portal EJA' para ser utilizada integralmente ou em partes nos cursos formais e informais. Esta coleção é composta por 13 cadernos temáticos destinados aos alunos e outros 14 destinados aos professores, totalizando 27.

No mesmo ano, o Governo criou o Programa Nacional de Alfabetização de Jovens e Adultos - PNLA, criado pela Resolução no 18, de 24 de abril de 2007, visando distribuir, a título de doação, livros didáticos às entidades parceiras do programa. 
Dessa maneira, a produção de materiais didáticos para a EJA acompanha toda uma complexa realidade, sendo tão dispersa quanto às iniciativas e os cursos. Tamanha diversidade de livros didáticos dificulta o recorte no universo desses recursos, uma vez que não seria possível analisar ou mesmo agrupar e tipificar todas as obras disponíveis. Por este motivo, o material da SECAD, elaborado pela parceria entre Governo Federal e a fundação Unitrabalho, foi selecionado como objeto de estudo do presente trabalho devido ao seu alcance nacional e caráter oficial.

\section{MATERIAIS E MÉTODOS}

Esta pesquisa consiste em um estudo de caso de abordagem qualitativa (SAMPIERI, COLLADO e LUCIO, 2013). O objeto de análise foi o caderno Cultura e Trabalho (MEC, 2007), que compreende um dos 13 cadernos voltados à EJA disponibilizados pelo Governo Federal para acesso e download públicos. Este material foi selecionado pela abrangência do tema abordado - Cultura. O caderno apresenta 64 páginas, cujo conteúdo é composto por 24 textos, os quais são ilustrados pelo total de 54 imagens.

A análise das imagens segue as quatro etapas do método de Barros (2009). Em um primeiro momento, visando conhecer o conteúdo, foi realizada uma leitura exploratória do caderno. Em seguida, com o auxílio de uma planilha, todas as imagens foram classificadas de acordo com os níveis de expressão propostos por Dondis (2007): Representacional, Abstrato ou Simbólico; realizando-se uma soma simples para registrar a quantidade de imagens contempladas em cada nível de expressão.

[...] representacional - aquilo que vemos e identificamos com base no meio ambiente e na experiência; o abstrato - a qualidade cinestésica de um fato visual reduzido a seus componentes visuais básicos e elementares enfatizando os meios mais diretos, emocionais e mesmo mais primitivos da criação de mensagens e o simbólico - o vasto universo de sistemas de símbolos codificados que o homem criou arbitrariamente e ao qual atribui significados (DONDIS, 2007, p.84).

A autora (op cit, p.103) ainda esclarece que apesar das características específicas de cada nível, essas não são antagônicas, pelo contrário, tais características se sobrepõem e se reforçam mutuamente. Pretende-se assim, indicar a predominância do nível encontrada em cada imagem do caderno.

$\mathrm{Na}$ terceira etapa, apenas as imagens de nível de expressão Simbólico foram consideradas - uma vez que ele permite ampliar as interpretações para além do conteúdo verbal e considerar a significação cultural das imagens. Nela investigou-se a relação entre as informações verbais e não verbais, as quais foram dividas nas seguintes categorias: Informação visual principal (imagem que é a própria composição do conteúdo na página, ou que complementa a compreensão do texto verbal como novos dados); Informação visual complementar (imagem subordinada ao conteúdo verbal, a qual facilita a compreensão do texto); e Informação visual decorativa (imagem de função estritamente estética, não oferecendo extensões de conteúdo significativas para a compreensão).

Por fim, nas imagens classificadas como Principal ou Complementar avaliou-se a integração do conteúdo visual e verbal, com vistas a reconhecer a possibilidade de exploração dessas composições como recurso para leitura visual crítica. 


\section{RESULTADOS E DISCUSSÕES}

A análise foi realizada em todas as 54 imagens encontradas no caderno. $\mathrm{Na}$ Figura 1, a seguir, o procedimento é detalhado em exemplos de cada categoria estabelecida. Nesta figura estão presentes seis páginas do caderno, sendo duas simples e duas duplas.

A primeira página (Figura $1 \mathrm{~A}$ ) apresenta um conteúdo verbal referente à receita da Maniçoba - prato típico da Região Norte. Seu conteúdo imagético é composto por desenhos dos ingredientes em traços e cores, a figura está posicionada entre o título e o início do texto, levemente desalinhada nas laterais da coluna de texto, e quanto à hierarquia de informações, trata-se de um elemento subordinado e complementar ao título. Essa ilustração foi classificada com predominância Representacional, na medida em que sua significação estabelece uma relação direta com a preparação do prato.

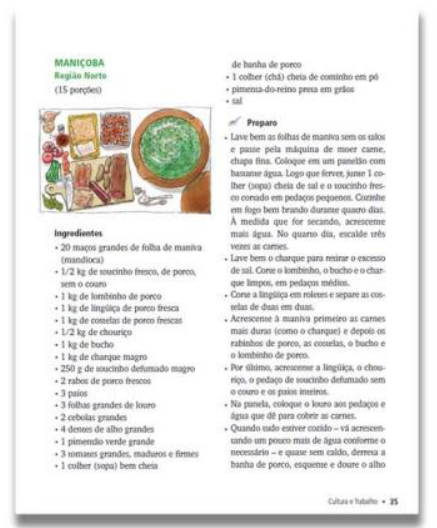

A

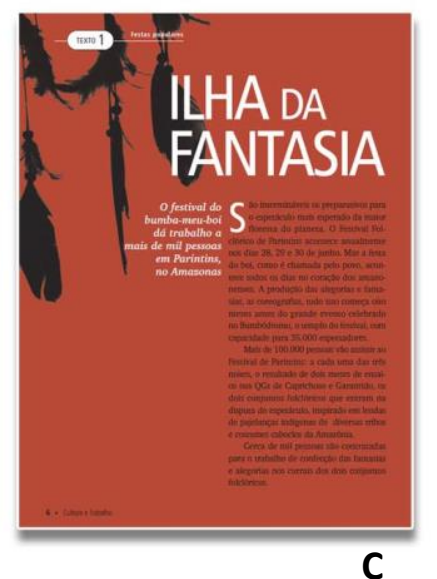

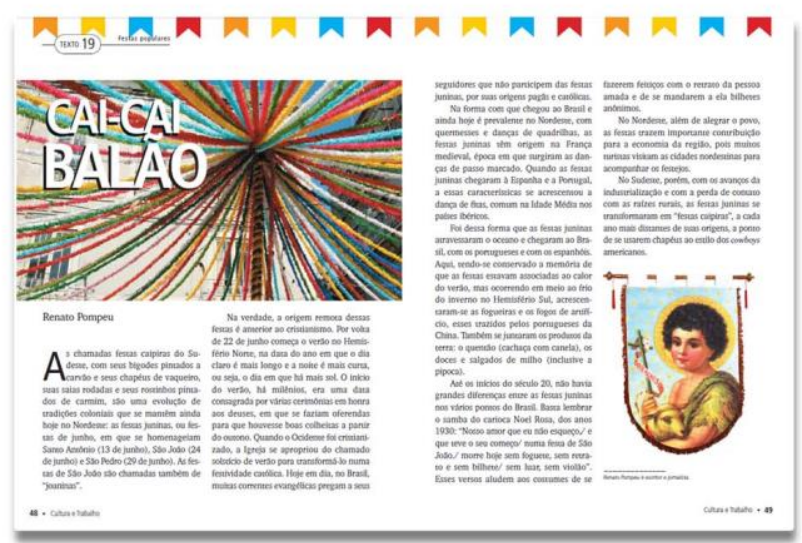

B

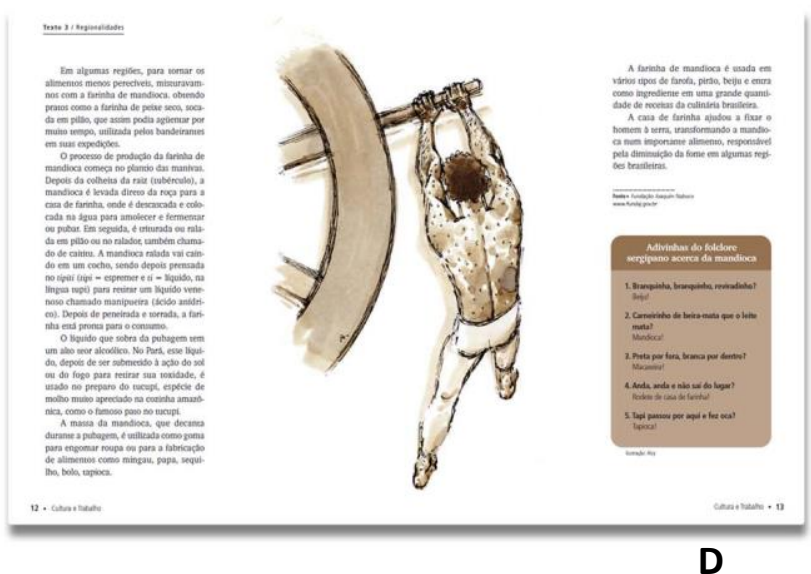

Figura 1 - Exemplos dos tipos de imagens encontradas no caderno Fonte: MEC, 2007

Na segunda página (Figura 1B) o texto verbal trata das festas juninas. As três imagens da página dupla representam elementos típicos usados nesses eventos. A primeira é um desenho simplificado de bandeiras composta por planos geométricos em diversas cores distribuídas linear e uniformemente no topo da página. A próxima ilustração é uma fotografia colorida de um plano fechado da decoração do local, esta foi posicionada na abertura do texto integrada ao título, ocupando duas colunas de 
texto e lateralmente ampliada, criando um ponto de atenção que condiz com a condição hierárquica do título. A terceira imagem é a fotografia em cores apenas da bandeira de Santo, típica do evento, esta respeita a linha lateral sugerida pela coluna de texto e está posicionada ao final de página, fechando a composição após o final do conteúdo verbal. Retomando a figura das bandeiras, para análise em específico, ela constitui um símbolo tradicional desses eventos motivo de ser classificado como Simbólico, e sendo um exemplo de Informação Visual Decorativa, no sentido em que a mesma não acrescenta informação ao conteúdo do texto verbal.

$\mathrm{Na}$ terceira página (Figura 1C) o conteúdo verbal refere-se ao festival do bumba-meu-boi. Sua imagem é uma fotografia em alto contraste das penas em preto na página de fundo vermelho, a figura ocupa cerca de $1 / 4$ da página e está integrada às informações textuais, sendo que ela contribui na hierarquia da leitura do conteúdo por sua posição junto ao título e direcionamento propício ao sentido de leitura. A ilustração é um exemplo de imagem Simbólica e Complementar, na medida em que as fantasias são um símbolo da festa e a imagem de um detalhe em destaque favorece a complementação do texto verbal, pelos elementos utilizados que permitem diferentes interpretações e significações culturais.

Na quarta página (Figura 1D) o conteúdo escrito explora brevemente a história da produção de farinha de mandioca no Brasil. Sua ilustração consiste em um desenho de um escravo trabalhando na moenda com traços característicos e utilizando apenas duas cores. É uma figura grande que ocupa metade das páginas, sendo um elemento central na composição e um fator de atração visual. Tal imagem foi categorizada como exemplo de Simbólica, justamente pelo uso do escravo como umas das principais forças de trabalho envolvidas na produção da farinha, e Informação Visual Principal, considerado que durante o texto não há menção direta ao trabalho escravo, evocando pré-conhecimentos a respeito do conteúdo, e permitindo, dessa maneira, a ampliação do conteúdo verbal a partir do visual.

A partir dessas análises, os resultados completos do estudo revelaram que do total de 54 imagens presentes no caderno $65 \%$ foram classificadas como do predominantemente Representacional, o restante se dividiu entre $33 \%$ no nível Simbólico e $2 \%$ no nível abstrato, como pode ser observado na Tabela 1.

Tabela 1 - Níveis de expressão da imagem no caderno Cultura e Trabalho

\begin{tabular}{lcc}
\hline & Quantidade de imagens & Porcentagem no caderno \\
\hline Representacional & 35 & $65 \%$ \\
\hline Abstrato & 1 & $2 \%$ \\
\hline Simbólico & 18 & $33 \%$ \\
\hline Total de imagens & 54 & $100 \%$ \\
\hline
\end{tabular}

Fonte: Elaborado pelo autor, com base na pesquisa realizada.

$\mathrm{Na}$ terceira fase, estabelecendo o foco nas 18 imagens identificadas como principalmente Simbólicas buscou-se elucidar os níveis de relação entre as informações verbais e não-verbais presentes nos textos que as contém. Das 18 imagens, seis apresentaram-se como Informações Visuais Principais - permitindo interpretações mais amplas - cinco apresentaram-se como Informações Visuais Complementares - tendo como papel específico complementar o conteúdo do texto - 
e sete apresentaram-se como Informações Visuais Decorativas - cujo principal apelo é estético, como mostrado na Tabela 2.

Tabela 2 - Níveis de relação entre informações verbais e não verbais nas imagens simbólicas

\begin{tabular}{lcc}
\hline & Quantidade de imagens & Porcentagem no caderno \\
\hline Informação Visual Principal & 6 & $33 \%$ \\
\hline Informação Visual Complementar & 5 & $28 \%$ \\
\hline Informação Visual Decorativa & 7 & $39 \%$ \\
\hline Total de imagens Simbólicas & 18 & $100 \%$ \\
\hline
\end{tabular}

Fonte: Elaborado pelo autor, com base na pesquisa realizada.

Os resultados completos das etapas dois e três reforçaram as conclusões encontradas em literatura de que em sua maioria os materiais didáticos valem-se de imagens mais como um elemento de representação da realidade, do que como um texto visual com maior possibilidade de interpretações.

Nas imagens Simbólicas, apesar da proximidade de resultados, quando as mesmas são empregadas como Informação Visual Principal ou Complementar ao texto verbal a exploração das várias possibilidades de interpretação das mesmas podem auxiliar de maneira importante no letramento visual dos alunos. Ainda assim, dos 33\% de imagens Simbólicas identificadas entre as 54 analisadas, apenas 20\% correspondem aos níveis Principal e Complementar. Nesse estudo de caso, os números revelam um grande espaço ainda disponível para a exploração da imagem como potencial elemento de extensão da leitura e como recurso didático na formação de adultos que possuem conhecimentos prévios a serem valorizados e trabalhados pedagogicamente.

\section{CONSIDERAÇÕES FINAIS}

Palavras e imagens, ao comporem os processos de comunicação contribuem para o entendimento dos significados histórico e cultural que integram a mensagem. $E$ no caso de materiais de ensino e aprendizagem as habilidades de compreensão e interpretação de informações visuais podem ser tão importantes quanto àquelas voltadas ao letramento verbal.

As pesquisas encontradas atestam a relevância da imagem na composição dos materiais didáticos, todavia, relatam que seu emprego nem sempre considera as suas reais potencialidades no que tange à transmissão de conhecimentos e fomento ao pensamento crítico. Também alertam para a necessidade de se atentar às diferentes linguagens presentes nos textos.

No caso do EJA, cuja produção de recursos didáticos ainda encontra-se em vias de desenvolvimento, tais ações aplicadas em futuros projetos podem incentivar a elaboração de mais atividades de leitura visual crítica em aula. Gerando oportunidades de formação para a leitura e a compreensão de imagens no contexto, ultrapassando suas meras atribuições estéticas. As Teorias utilizadas nesse estudo de caso poderiam servir como uma referência para criação futura de diretrizes para avaliação e planejamento gráfico da linguagem visual nos recursos didáticos. Visando o aprimoramento da relação entre os conteúdos verbal e não verbal, e explorando as possibilidades interpretativas de ambas as linguagens. 
Quanto à situação atual, a reflexão sobre o emprego de imagens na alfabetização de jovens e adultos revelou a oportunidade para o desenvolvimento da leitura crítica, orientada por saberes mais especializados. De modo específico, considerada toda a experiência anterior desses alunos, entende-se que as ilustrações e a linguagem visual adotadas precisam ser diferentes dos livros de alfabetização infantil. Permitindo reflexões sobre o conteúdo e até evocando pré-conhecimentos a respeito do assunto em questão. Uma sugestão nesse sentido seria abrir essa discussão aos docentes, os quais são os responsáveis pela mediação desses conteúdos.

Enfim, a partir da análise do objeto de estudo, os resultados encontrados corroboram com as conclusões de pesquisas anteriores e reforçam a importância de se ampliar as discussões acerca do tema, no sentido de aprimorar os projetos em design de materiais didáticos, em específico daqueles voltados à formação de jovens e adultos.

\section{REFERÊNCIAS}

AMARAL, T. T. B.; FISCHER, A. Abordagem da imagem em um livro didático voltado para a alfabetização: perspectivas de letramento visual. In: BAKHTINIANA - Revista de Estudos do Discurso, v.8, n.2. São Paulo, jul./dez. 2013. P.5-23.

ANDRADE NETO, M. L.; HARADA, T.; DOMINGUES, L. F. V.; LANDIM, P. C. O design de livro didático no Brasil: um estudo infométrico. In: CONGRESSO BRASILEIRO DE PESQUISA E DESENVOLVIMENTO EM DESIGN, 10. 2012, São Luís. Anais... Rio de Janeiro: ANPeD/AEnD-Br, 2012.

BARROS, C. G. P. Capacidades de leitura de textos multimodais. In: POLIFONIA, v. 16, n. 19. Cuiabá, 2009. P.161-186.

BARROS, C. G. P.; COSTA, E. P. M. Os gêneros multimodais em livros didáticos: formação para o letramento visual? In: BAKHTINIANA - Revista de Estudos do Discurso, v.7, n.2. São Paulo, jul/dez 2012. P.38-56.

BRASIL, Casa Civil. Lei no 9.394 de 20 de dez de 1996: Estabelece as diretrizes e bases da educação nacional. Brasília: 20 dez. 1996. Disponível em: <http://www.planalto.gov.br/ccivil_03/leis/l9394.htm>. Acesso em: 15 jun. 2013.

BELMIRO, C. A. A imagem e suas formas de visualidade nos livros didáticos de Português. EDUCAÇÃO \& SOCIEDADE, v.21, n.72. Campinas, ago. 2000. P.11-31.

COUTINHO, S. G.; LOPES, M. T.; CADENA, R. A. Ensina Design: mapeamento do uso da linguagem gráfica no ensino fundamental brasileiro. In: CONGRESSO INTERNACIONAL DE DESIGN DA INFORMAÇÃO, 5. 2011, Florianópolis. Anais... Bauru: SBDI, 2011.

DONDIS, D. A. Sintaxe da linguagem visual. São Paulo: Martins Fontes, 2007.

FARBIARZ, J. L.; FARBIARZ, A.; COELHO, L. A. (Orgs.). Os Lugares do Design na Leitura. Teresópolis: Novas Idéias, 2008.

FREIRE, V. E. C. A eficácia de imagens em livros didáticos infantis de língua portuguesa: parâmetros e recomendações para seu uso. 2008. 105 f. Dissertação (Mestrado) - Universidade Federal de Pernambuco, Curso de Pós-graduação em Design.

MARSHALL, L.; MEACHEM, L. Como usar imagens. São Paulo: Rosari, 2010. 
MEC - Ministério da Educação. Cultura e Trabalho. Coleção Cadernos de EJA. São Paulo: Unitrabalho/SECAD, 2007. Disponível em: <http://portal.mec.gov.br/secad/ arquivos/pdf/01_cd_al.pdf>. Acesso em 20 jan. 2014.

MELLO, P. E. D. Material didático para educação de jovens e adultos: história, formas e conteúdos. 2010. 254 f. Tese (doutorado) - Faculdade de Educação da Universidade de São Paulo, Curso de Pós-graduação em Educação.

MORAES, D. D. C. D. Visualidade do livro didático no Brasil: o design de capas e sua renovação de 1970 e 1980. 2010. 182 f. Dissertação (Mestrado) - Faculdade de Educação da Universidade de São Paulo, Curso de Pós-graduação em Educação.

PIZARRO, M. V. Histórias em quadrinhos e o ensino de Ciências nas séries iniciais: estabelecendo relações para o ensino de conteúdos curriculares procedimentais, 2009, 188f. Dissertação (Mestre) - Faculdade de Ciências da UNESP, Curso de Pósgraduação em Educação para a Ciência.

SAMPIERI, R. H.; COLLADO, C. F.; LUCIO, M. P. B. Metodologia de pesquisa. 5. ed. Porto Alegre: Penso, 2013.

TEIXEIRA, N. S.; BRITO, L. C. C. A Linguagem Visual do Livro Didático. In: CONGRESSO BRASILEIRO DE PESQUISA E DESENVOLVIMENTO EM DESIGN, 9. 2010, São Paulo. Anais... Rio de Janeiro: ANPeD/AEnD-Br, 2010. 